\title{
ECONOMÍA, MERCADO Y BIENESTAR HUMANO DURANTE LA GUERRA CIVIL ESPAÑOLA
}

\author{
JAVIER PUCHE (UNIZAR) \\ Universidad de Zaragoza \\ Facultad de Ciencias Sociales y Humanas de Teruel \\ Ciudad Escolar s/n - 44003 Teruel (España) \\ jpuche@,unizar.es
}

\begin{abstract}
Resumen:
Este artículo ofrece una visión de conjunto de la economía española y el bienestar humano durante el periodo de la Guerra Civil de 1936-1939. A partir de análisis de los principales indicadores económicos y de salud, estudia el impacto que el conflicto bélico de 1936-1939 tuvo en la economía española y en el bienestar humano de las poblaciones españolas. Los resultados revelan que la guerra truncó la tendencia de crecimiento económico del primer tercio del siglo $\mathrm{XX}$, que supuso la ruptura de un mercado que había funcionado hasta entonces de manera integrada, y que la mayor parte de la población española conoció una fuerte regresión de sus condiciones de vida y salud. Las consecuencias de la Guerra Civil y, más aún, la autarquía franquista propiciaron una nueva fase de divergencia con la Europa avanzada en términos de desarrollo económico y bienestar humano.
\end{abstract}

Palabras clave:

Economía española - mercado - bienestar humano - Guerra Civil de 1936-1939

\begin{abstract}
:
This article shows an overview of the Spanish economy and human welfare during the Civil War period from 1936 to 1939. Based on analysis of the main economic and health indicators, it analyzes the impact of the armed conflict of 1936-1939 on the Spanish economy and human welfare of Spanish populations. The results reveal that the war truncated the trend of economic growth of the first third of the twentieth century, what meant the rupture of a market that had operated up to then in an integrated way. A strong regression of their living and health conditions was experienced by most of the Spanish population. Civil War consequences and, even more, Franco's autarky led to a new divergence period against the most advanced Europe in terms of economic development and human well-being.
\end{abstract}

\section{Keywords:}

Spanish Economy - Market - Human Welfare - Civil War period: 1936-1939 


\title{
ECONOMÍA, MERCADO Y BIENESTAR HUMANO DURANTE LA GUERRA CIVIL ESPAÑOLA
}

\author{
JAVIER PUCHE (UNIZAR)
}

jpuche@unizar.es

\section{Introducción}

A lo largo del siglo XIX, España, por motivos particulares, al igual que aconteciera con otros países de la periferia europea, sufrió un notable retraso con respecto a las naciones que lideraron la primera industrialización. Ello tuvo implicaciones directas para el nivel de vida y bienestar de su población ${ }^{1}$. Pese a unas pautas tardías de desarrollo industrial y modernización económica ${ }^{2}$, las estimaciones macroeconómicas sitúan los comienzos del crecimiento económico moderno español a mediados del siglo XIX, cuya trayectoria se caracterizaría por una continuidad en las pautas de crecimiento del PIB a largo plazo, entre 1850 y 1929. Este progreso económico, sin embargo, se fracturaría con la crisis internacional de los años treinta y, mucho más aún, por la Guerra Civil de 1936-1939 y la cerrada autarquía del primer franquismo3.

Frente al tópico, muy arraigado, según el cual España no estuvo especialmente afectada por la Gran Depresión de los años treinta, lo cierto es que la evolución del PIB de 1929-1935 no registra prácticamente ninguna mejora, mientras que el PIB per cápita disminuyó en un 1,30\% anual. La crisis internacional afectó seriamente a los sectores exportadores e importadores y redujo la inversión extranjera. La explicación radica en que la protección exterior (aranceles y depreciación de la divisa) existente en 1929 fue insuficiente para evitar el contagio de la crisis internacional ${ }^{4}$. En cualquier caso, el impacto de la Guerra Civil de 1936-1939 y la ausencia de reconstrucción económica tras el conflicto, por causa de la política autárquica y del aislamiento internacional de la primera década de la dictadura franquista, se revelan como la etapa de mayor divergencia de la economía española en el siglo $\mathrm{XX}^{5}$. Las destrucciones materiales ocurridas durante la guerra, los efectos causados por el conflicto sobre el desarrollo de los principales sectores productivos, así como sobre las pautas de cambio estructural, la ruptura de la unidad de mercado y la muerte o el exilio de muchos obreros especializados, expertos o técnicos, constituyeron un importante lastre para la economía española ${ }^{6}$. Un indicador resume del modo

\footnotetext{
1 Prados de la Escosura, Leandro, El progreso económico de España, 1850-2000, Madrid, Fundación BBVA, 2003; Martínez Carrión, José Miguel, "El debate sobre el atraso económico de España”, en Barciela, Carlos; Chastagnaret, Gérard y Escudero, Antonio (eds), La Historia Económica en España y Francia (siglos XIX y XX), Alicante, Universidad de Alicante/Casa de Velázquez, 2006, págs. 351-402; Maluquer de Motes, Jordi, La economía española en perspectiva histórica, Barcelona, Pasado y Presente, 2014; y Maluquer de Motes, Jordi, España en la economía mundial. Series largas para la economía española, Madrid, Instituto de Estudios Económicos, 2016.

2 A comienzos del siglo XX la economía española seguía siendo fundamentalmente agraria: todavía en 1913, en vísperas de la Primera Guerra Mundial, el 57\% de la población activa continuaba trabajando en el sector agrario, aunque únicamente producía un 30\% de la renta nacional, en Prados de la Escosura, Leandro, El progreso económico..., op. cit., pág. 587.

3 Prados de la Escosura, Leandro, El progreso económico..., op. cit.; y Maluquer de Motes, Jordi, España en la economía mundial..., op. cit.

${ }^{4}$ Comín, Francisco, “La Gran Depresión y la Segunda República”, Negocios, El País, 29 de enero de 2012.

5 Prados de la Escosura, Leandro, El progreso económico..., op. cit.; y Maluquer de Motes, Jordi, España en la economía mundial..., op. cit.

${ }^{6}$ Pero, aunque la dictadura franquista utilizó estos factores como elementos de propaganda para justificar la mala situación económica de la inmediata posguerra, el deterioro del equipo productivo no fue en ningún caso tan grave como para motivar ni la negativa evolución de los años inmediatamente posteriores a 1939 ni la lentitud para
} 
más expresivo sus consecuencias últimas: la renta per cápita española en relación a la media de Italia, Francia, Alemania y Reino Unido descendió desde el 64,6\% en 1935 al 42,8\% en 19397. Todo un lustro, pues, perdido, en términos de ganancias de bienestar y de convergencia con la Europa avanzada. El desplome económico, además, tuvo efectos terribles sobre la sociedad, reflejado en un deterioro general de las condiciones de vida y salud ${ }^{8}$.

Este artículo analiza el impacto que la Guerra Civil de 1936-1939 tuvo en la economía española y en el bienestar humano de las poblaciones españolas. De este modo, se pretende evaluar los efectos que el golpe de Estado militar de julio de 1936, la ruptura del mercado interior que éste provocó y la dureza y profundidad de la conflagración tuvieron, por un lado, en el sistema productivo y en las principales macromagnitudes económicas y, por otro, en el bienestar humano y la salud de las poblaciones españolas durante el periodo comprendido entre 1936 y 1939. Aunque es cierto que ya existen estudios precedentes sobre el comportamiento de la economía española en la Guerra Civil ${ }^{9}$, este artículo ofrece una visión de conjunto, reseñando las principales conclusiones aportadas por la historiografía económica española en los últimos tiempos. El trabajo se estructura en cuatro partes. Tras esta introducción, en la segunda parte se analiza el coste macroeconómico de la Guerra Civil española, como un conjunto, empleando magnitudes colectivas, como las ramas productivas, el grado de apertura comercial, la renta nacional, la renta por habitante o el consumo privado. No obstante, como la consecuencia inmediata y más importante desde el punto de vista económico de la guerra fue la ruptura del mercado nacional, esta parte dedicará también un espacio a examinar la evolución económica tanto en la zona republicana como en la zona rebelde. Posteriormente, en la tercera parte se estudian los efectos que la contienda provocó en las condiciones de vida y salud de la población. Para ello nos serviremos del análisis de los principales indicadores de salud y del estado nutricional, como la tasa bruta de mortalidad infantil, la esperanza de vida al nacer y la estatura, así como de índices sintéticos, como el Índice de Desarrollo Humano (IDH). El artículo finaliza con el cuarto apartado, que sintetiza las conclusiones finales.

\section{El coste macroeconómico de la Guerra Civil}

Desde finales del siglo XIX, la economía española había crecido a ritmos modestos pero sostenidos, iniciando un cierto cambio estructural, de diversificación y de difusión industrial a zonas nuevas, que culminaría en el primer tercio del siglo XX. Dentro de esta fase de crecimiento pausado, la década de 1920 significó la definitiva aceleración de la industrialización que se alcanza, desde el comienzo de la centuria, con una población que aumenta con rapidez y con cambios igualmente importantes en las estructuras productivas ${ }^{10}$. La Gran Depresión de los años treinta y, sobre todo, la Guerra Civil y la autarquía franquista, ocasionarán la brusca interrupción

recuperar el nivel de actividad que había antes del conflicto. Como ha señalado Carlos Barciela, no podemos traducir en un único dato el coste del conflicto. En cualquier caso, es evidente que la guerra no fue tan destructiva como la propaganda franquista se empeñó en sostener durante décadas. Para el fracasado, también en términos económicos, régimen franquista, culpar a los "rojos" del desastre productivo se convirtió en una gran coartada de su propia ineficacia, en Barciela, Carlos, "La Economía y la Guerra”, Pasado y Memoria, 8, 2009, págs. 13-34.

${ }^{7}$ Carreras, Albert, "La industrialización: una perspectiva a largo plazo", Papeles de Economía Española, 73, 1997, pág. 52.

${ }^{8}$ Del Cura, Ma Isabel y Huertas, Rafael, Alimentación y enfermedad en tiempos de hambre. España, 1937-1947, Madrid, CSIC, 2007.

${ }^{9}$ Entre otros estudios, destaca la monografía coordinada por Martín Aceña, Pablo y Martínez Ruiz, Elena (eds), La economía de la guerra civil, Madrid, Marcial Pons, 2006.

10 La economía española creció fuertemente entonces gracias al gran impulso recibido de la explotación de los recursos hidroeléctricos y pudo disponer de un gran volumen de divisas, consiguiendo un importante incremento de las importaciones de bienes de equipo y de la inversión privada y pública, en Maluquer de Motes, Jordi, La economía española..., op. cit., págs. 168-179. 
de todo ello, con secuelas que tardarán en superarse. Aunque las macromagnitudes económicas obligan a calificar la crisis económica española de muchos menos grave que la de otros países europeos, la Gran Depresión de los años treinta se dejó sentir, especialmente en los sectores más abiertos al mercado exterior. De ahí que la historiografía económica haya podido establecer que lo que hubo en España entre 1930 y 1935 fue un estancamiento o una somera depresión. Eso sí, la recuperación que se dejó sentir en otros países a partir de 1933 fue, en el caso español, apenas perceptible ${ }^{11}$. Como resultado, tanto el ingreso real por habitante como los niveles relativos de bienestar empeoraron moderadamente para los españoles (Gráfico 1). Tras el fracaso del golpe de Estado militar de los generales rebeldes, en julio de 1936, las fortísimas perturbaciones económicas que siguen a la Guerra Civil en los tres años siguientes desencadenarán un auténtico desplome de lo que había sido una moderada pero tenaz ganancia de niveles de vida y prosperidad en el primer tercio del siglo XX, y un freno en procesos de cambio estructural que sólo se retomarán pasado el ecuador de la centuria. El Gráfico 1, tan aleccionador, lo justifica bien: cuando termina la contienda, en 1939, la renta real per cápita de los españoles había retrocedido, en términos reales, a los niveles de comienzos del siglo XX. También entre 1935 y 1939 el nivel previamente alcanzado de convergencia real de España con la Europa más próspera no dejó de caer -del 64,6\% al 42,8\% entre ambos años-, necesitándose después bastantes años más, hasta comienzos de la década de 1970, para recuperar la cota inicial.

\section{Grafico 1. PIB per cápita español, 1925-1940}

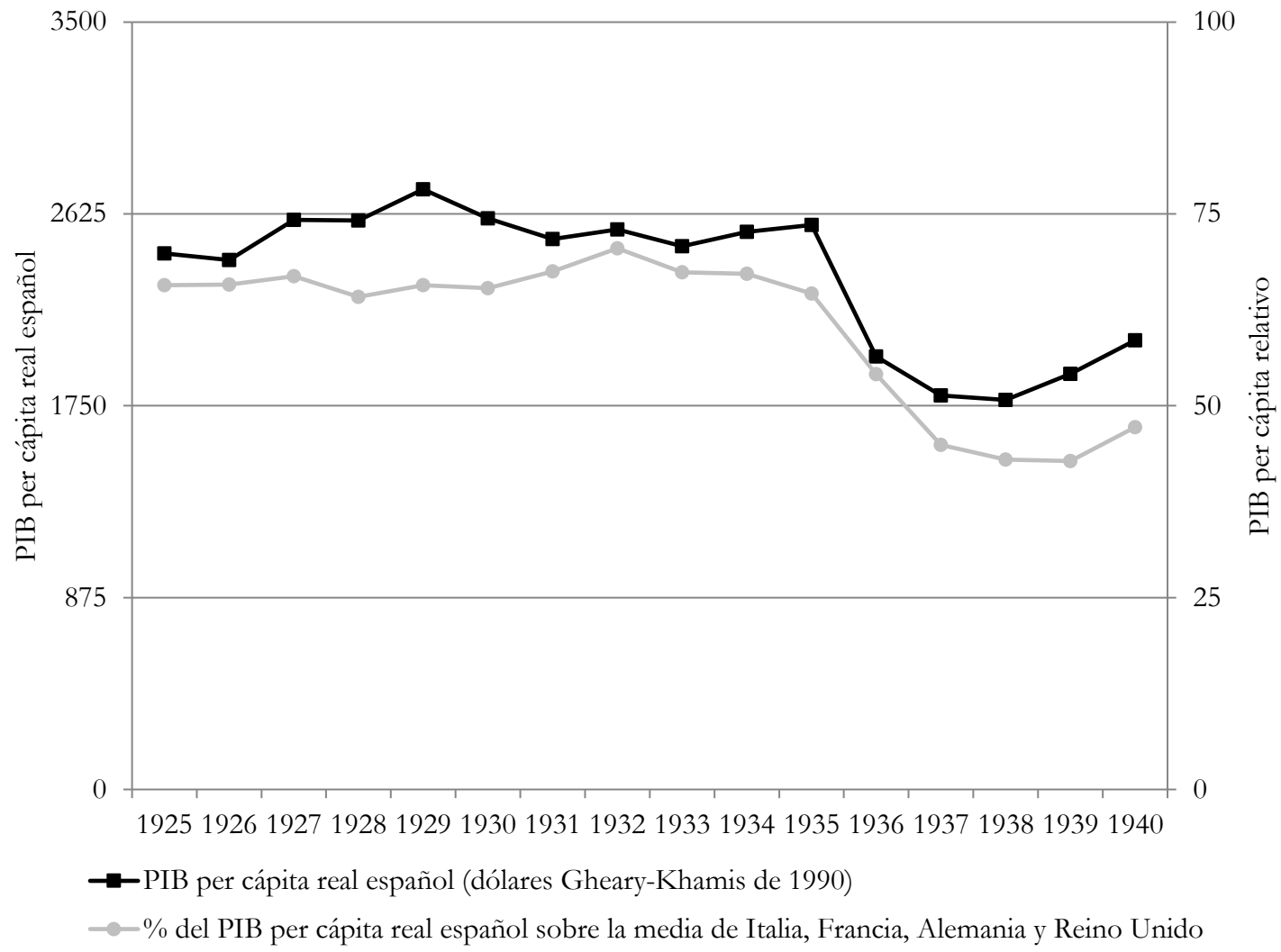

Fuente: Carreras, Albert; Prados de la Escosura, Leandro y Rosés, Joan R., "Renta y riqueza", en Carreras, Albert y Tafunell, Xavier (eds.), Estadísticas Históricas de España, Barcelona, Fundación BBVA, 2005, pág. 1363; y Carreras, Albert, "La industrialización..., op. cit., pág. 52. Elaboración propia.

11 Comín, Francisco, "La economía española en el periodo de entreguerras (1919-1935)", en Nadal, Jordi, Carreras, Albert y Sudriá, Carles (comps), La economía española en el siglo XX. Una perspectiva histórica, Barcelona, Ariel, 1987, págs. 105-149. 
La política económica republicana no causó la depresión económica ni desencadenó la Guerra Civil $^{12}$. El origen de la Guerra Civil no fue económico, sino que estuvo, según la historiografía española, en un doble fracaso militar: el golpe de Estado de los generales rebeldes no triunfó, en julio de 1936, y el Gobierno de la República no logró aplastar el levantamiento. La inclinación del Ejército español a los pronunciamientos no era una novedad. Lo que había cambiado era el contexto internacional. La ayuda financiera y militar de las potencias fascistas al bando rebelde y el abandono de las democracias europeas al Gobierno de la República permitieron el triunfo de los generales sublevados, pero después de una costosa y sangrienta Guerra Civil ${ }^{13}$.

Entre 1936 y 1939, el producto español cayó -entrando en valores negativos: en tasa media anual cerca del - $0,6 \%$ en el ciclo 1935-1944-, intensificándose el ciclo recesivo que había nacido con la Gran Depresión -menos profunda, de $-0,02 \%{ }^{14}$. Al estancamiento de la actividad económica agregada entre 1929 y 1935, siguió una contracción durante los años del conflicto civil (Tabla 1). Las principales ramas de actividad, es decir, la agricultura y la industria, sufrieron una fuerte caída en los primeros meses de la guerra. Probablemente, y de acuerdo con la información estadística disponible, la actividad en ambos sectores descendió entonces cerca de un tercio (Tabla 1). No se recuperaría en absoluto durante el transcurso de la contienda. En el estancamiento de la agricultura pesó decisivamente la falta de mano de obra y de abonos, además de los problemas de organización, especialmente en la zona republicana ${ }^{15}$. En el caso de la industria, la contracción fue ocasionada por la dificultades de abastecimiento de materias primas (incluido los recursos energéticos) y el acceso a los mercados ${ }^{16}$. El tráfico de mercancías y personas, dejando aparte el personal militar, debió de disminuir de manera aún más acusada, a juzgar por los datos disponibles sobre los resultados de explotación de las compañías ferroviarias ${ }^{17}$.

Tabla 1. Sectores productivos y PIB durante la Guerra Civil, 1936-1939 (1935=100)

\begin{tabular}{|c|c|c|c|c|c|}
\hline & $\begin{array}{c}\text { Agricultura, } \\
\text { ganadería y } \\
\text { pesca }\end{array}$ & Industria & $\begin{array}{c}\text { Construcción } \\
\text { y obras } \\
\text { públicas }\end{array}$ & Servicios & PIB \\
\hline 1935 & 100 & 100 & 100 & 100 & 100 \\
\hline 1936 & 67 & 72 & 82 & 88 & 77 \\
\hline 1937 & 71 & 64 & 68 & 77 & 70 \\
\hline 1938 & 67 & 68 & 57 & 78 & 68 \\
\hline 1939 & 77 & 75 & 71 & 81 & 76 \\
\hline
\end{tabular}

Fuente: Martín Aceña, Pablo, "La economía de la guerra civil: perspectiva general y comparada", en Martín Aceña, Pablo y Martínez Ruiz, Elena (eds), La economía de la guerra civil, Madrid, Marcial Pons, 2006, pág. 26.

\footnotetext{
${ }^{12}$ Comín, Francisco, “La Gran Depresión..., op. cit., pág. 25.

${ }^{13}$ Casanova, Julián y Gil Andrés, Carlos, Historia de España en el siglo XX, Barcelona, Ariel, 2009.

14 Prados de la Escosura, Leandro, El progreso económico..., op. cit., pág. 151.

15 Martínez Ruiz, Elena, "El campo en guerra: organización y producción agraria”, en Martín Aceña, Pablo y Martínez Ruiz, Elena (eds), La economía de la guerra civil, Madrid, Marcial Pons, 2006, págs. 107-159.

${ }^{16}$ Catalan, Jordi, “Guerra e industria en las dos Españas, 1936-1939”, en Martín Aceña, Pablo y Martínez Ruiz, Elena (eds), La economía de la guerra civil, Madrid, Marcial Pons, 2006, págs. 161-227.

17 Cayón, Francisco y Muñoz, Miguel, “Transportes y comunicaciones”, en Martín Aceña, Pablo y Martínez Ruiz, Elena (eds), La economía de la guerra civil, Madrid, Marcial Pons, 2006, págs. 229-272.
} 
El comercio exterior, considerado una palanca decisiva del crecimiento económico, se vio desigualmente afectado (Gráfico 2). Las exportaciones se redujeron a la mitad, lo que es imputable al estancamiento de la agricultura que atendía a los mercados internacionales. Las importaciones, según los estudios realizados, descendieron algo menos que las exportaciones. No obstante, si se tienen en cuenta las compras de armamento -no registradas en las estadísticas oficiales de comercio exterior- las importaciones en realidad se acrecentaron entre 1936 y $1938^{18}$. Pese a todo, durante los años de la Guerra Civil el grado de apertura de la economía española (porcentaje del comercio exterior en el PIB) disminuyó, al pasar del 9,4\% en 1935 al 4,5\% en 1939 (Gráfico 3). Esto revela que las repercusiones del conflicto sobre el comercio exterior fueron apreciables. El déficit del saldo comercial resultante, mayor que antes del comienzo de la guerra, obligó a acudir a fuentes externas de financiación ${ }^{19}$.

Gráfico 2. Exportaciones e importaciones españolas, 1925-1940 (en \% del PIB)

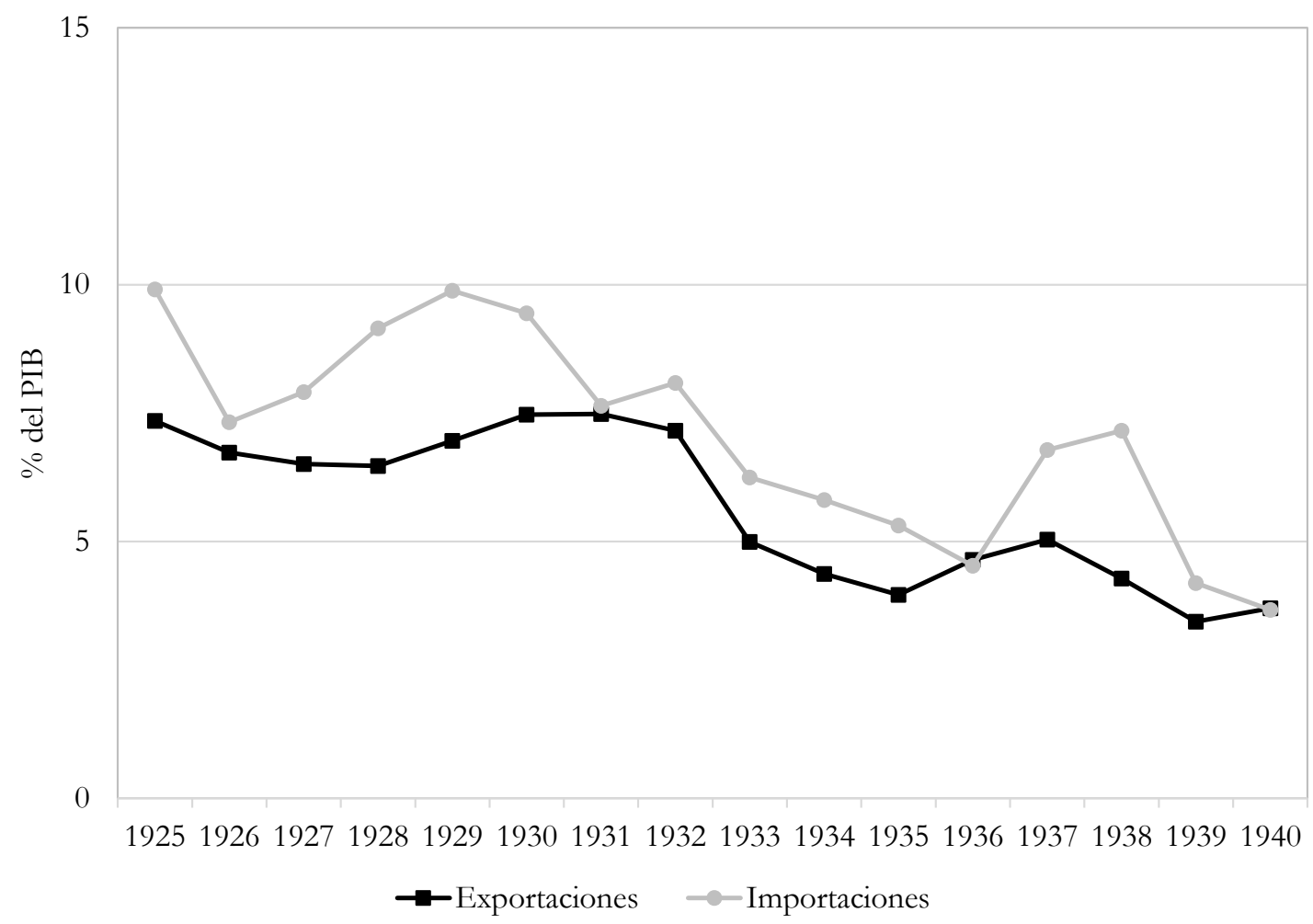

Fuente: Maluquer de Motes, Jordi, España en la economía mundial..., op. cit. págs. 137, 157. Elaboración propia

\footnotetext{
18 Martínez Ruiz, Elena, "Las relaciones económicas internacionales: guerra, política y negocios”, en Martín Aceña, Pablo y Martínez Ruiz, Elena (eds), La economía de la guerra civil, Madrid, Marcial Pons, 2006, págs. 273-327.

19 Sánchez Asiaín, José Ángel, La financiación de la guerra civil española. Una aproximación histórica, Crítica, Barcelona, 2012.
} 
Gráfico 3. Grado de apertura relativa de la economía española, 1925-1940 [(exportaciones + importaciones)/PIB] x100

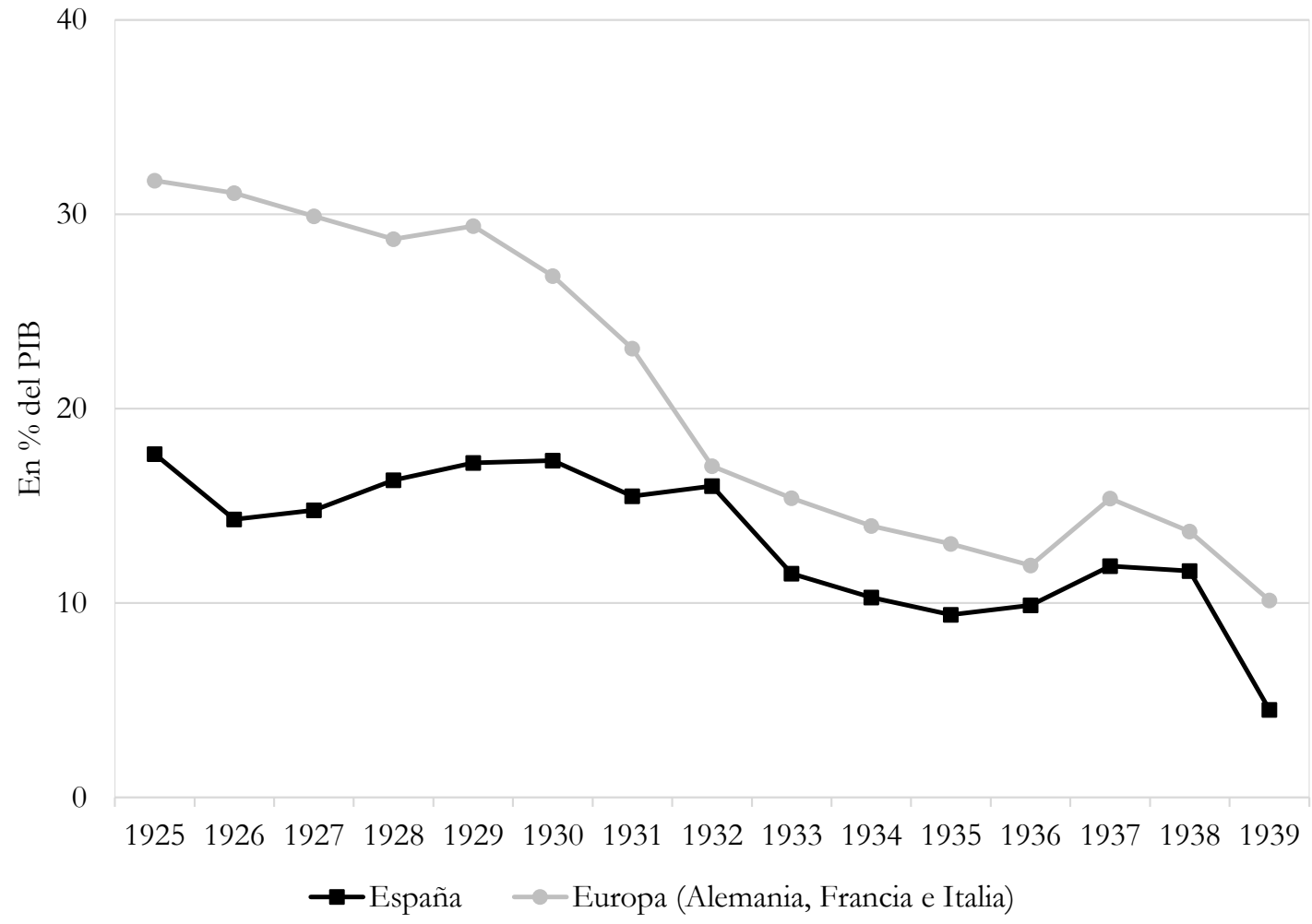

Fuente: Tena, Antonio, “Sector exterior”, en Carreras, Albert y Tafunell, Xavier (eds.), Estadísticas Históricas de España, Barcelona, Fundación BBVA, 2005, pág. 578. Elaboración propia.

Las finanzas públicas afrontaron también una situación crítica, debido al colapso de la recaudación tributaria, especialmente de los impuestos directos. Las autoridades de ambos bandos tuvieron que recurrir a fuentes de financiación interna de carácter extraordinario y apelar masivamente al crédito del Banco de España (de cada zona ${ }^{20}$. En cuanto al sistema financiero, funcionó de manera totalmente anormal durante el transcurso del conflicto. En su inicio padeció una crisis de liquidez, que se contuvo mediante un bloqueo de cuentas. La demanda crediticia, por su parte, se hundió por ausencia de actividad inversora y caída del consumo privado y las operaciones financieras experimentaron un fuerte declive por el efecto combinado del retroceso de la actividad económica, la desarticulación del comercio interior y el desbarajuste monetario ${ }^{21}$ (Tabla 2).

\footnotetext{
${ }^{20}$ Pons, Ma Ángeles, “La Hacienda pública y la financiación de la guerra”, en Martín Aceña, Pablo y Martínez Ruiz, Elena (eds), La economía de la guerra civil, Madrid, Marcial Pons, 2006, págs. 357-391.

${ }^{21}$ Martín Aceña, Pablo, "El sistema financiero", en Martín Aceña, Pablo y Martínez Ruiz, Elena (eds), La economía de la guerra civil, Madrid, Marcial Pons, 2006, págs. 393-429; y Sánchez Asiaín, José Ángel, La financiación..., op. cit.
} 
Tabla 2.Magnitudes de la economía española durante la Guerra Civil, 1936-1939 $(1929=100)$

\begin{tabular}{|c|c|c|c|c|c|}
\hline & $\begin{array}{l}\text { Consumo } \\
\text { privado }\end{array}$ & $\begin{array}{l}\text { Consumo } \\
\text { público }\end{array}$ & FBCF* & Exportaciones & Importaciones \\
\hline 1929 & 100,0 & 100,0 & 100,0 & 100,0 & 100,0 \\
\hline 1936 & 60,1 & 205,5 & 52,4 & 75,1 & 41,2 \\
\hline 1937 & 57,1 & 208,8 & 38,0 & 64,0 & 27,8 \\
\hline 1938 & 60,8 & 186,0 & 35,0 & 57,8 & 28,8 \\
\hline 1939 & 69,4 & 187,8 & 35,8 & 45,4 & 21,4 \\
\hline
\end{tabular}

* Formación bruta de capital fijo

Fuente: Martín Aceña, Pablo, “La economía de la guerra civil..., op. cit., pág. 24.

Si lo que antecede sirve para ofrecer una visión de conjunto del impacto macroeconómico de Guerra Civil, la historiografía matiza que no es posible analizar la evolución de la economía española durante el conflicto con el mismo prisma que en otros períodos históricos. Por un lado, porque aquélla dejó existir como una realidad unitaria al quedar dividido el territorio nacional en dos partes -en realidad, tres, ya que el territorio controlado inicialmente por el Gobierno de la República en la cornisa cantábrica no estaba conectado con el resto de la zona republicana (Mapa 1) -. La consecuencia inmediata y más importante desde el punto de económico de esta división territorial fue, como ha resaltado la historiografía económica española, la ruptura de la unidad del mercado ${ }^{22}$. Un mercado interior integrado significa la especialización productiva de las diferentes regiones en función de su dotación de factores, la existencia de relaciones comerciales, comunicaciones... que cubren y cohesionan todo el territorio nacional. Su división por la fuerza de las armas provocó enormes trastornos en el funcionamiento de la actividad económica. Así es, el inicio de la guerra supuso la ruptura de un mercado que había funcionado hasta entonces de manera integrada, y muchas empresas perdieron la relación con sus zonas de suministro o con sus mercados de venta, con sus deudores o sus acreedores. Por otro lado, la España republicana y la España controlada por los generales sublevados constituyeron dos modelos económicos diametralmente opuestos ${ }^{23}$. Por tanto, tenemos que examinarlos por separado, aunque nos interesemos por analizar los mismos aspectos.

Las zonas más industrializadas y económicamente más ricas, el País Vasco, Cataluña y Valencia, permanecieron fieles a la República, lo cual concedió a ésta una mejor situación de partida, que no iba a durar mucho. En Madrid estaban, además, las sedes de lo más importantes bancos y empresas, y las instituciones económicas centrales, empezando por el Banco de España con sus reservas de oro. En su contra tuvo la República, como se ha indicado, la discontinuidad territorial y el hecho de que las principales regiones agrícolas se decantaron a favor de los sublevados, lo que pronto crearía problemas de abastecimiento y $\operatorname{escasez}^{24}$ (Mapa 1). Pero, además, en el territorio fiel a la República, la entrega de armas a las organizaciones sindicales y el comienzo de

\footnotetext{
22 Martín Aceña, Pablo y Martínez Ruiz, Elena (eds), La economía de la guerra civil..., op. cit.

23 Carreras, Albert y Tafunell, Xavier, Historia económica de la España contemporánea (1789-2009), Crítica, Barcelona, 2010.

${ }^{24}$ Martínez Ruiz, Elena, “El campo en guerra..., op. cit., págs. 109-121.
} 
la guerra supuso la descomposición del Estado y el estallido de una revolución social de enormes dimensiones ${ }^{25}$.

\section{Mapa 1. División territorial de España en otoño de 1936}

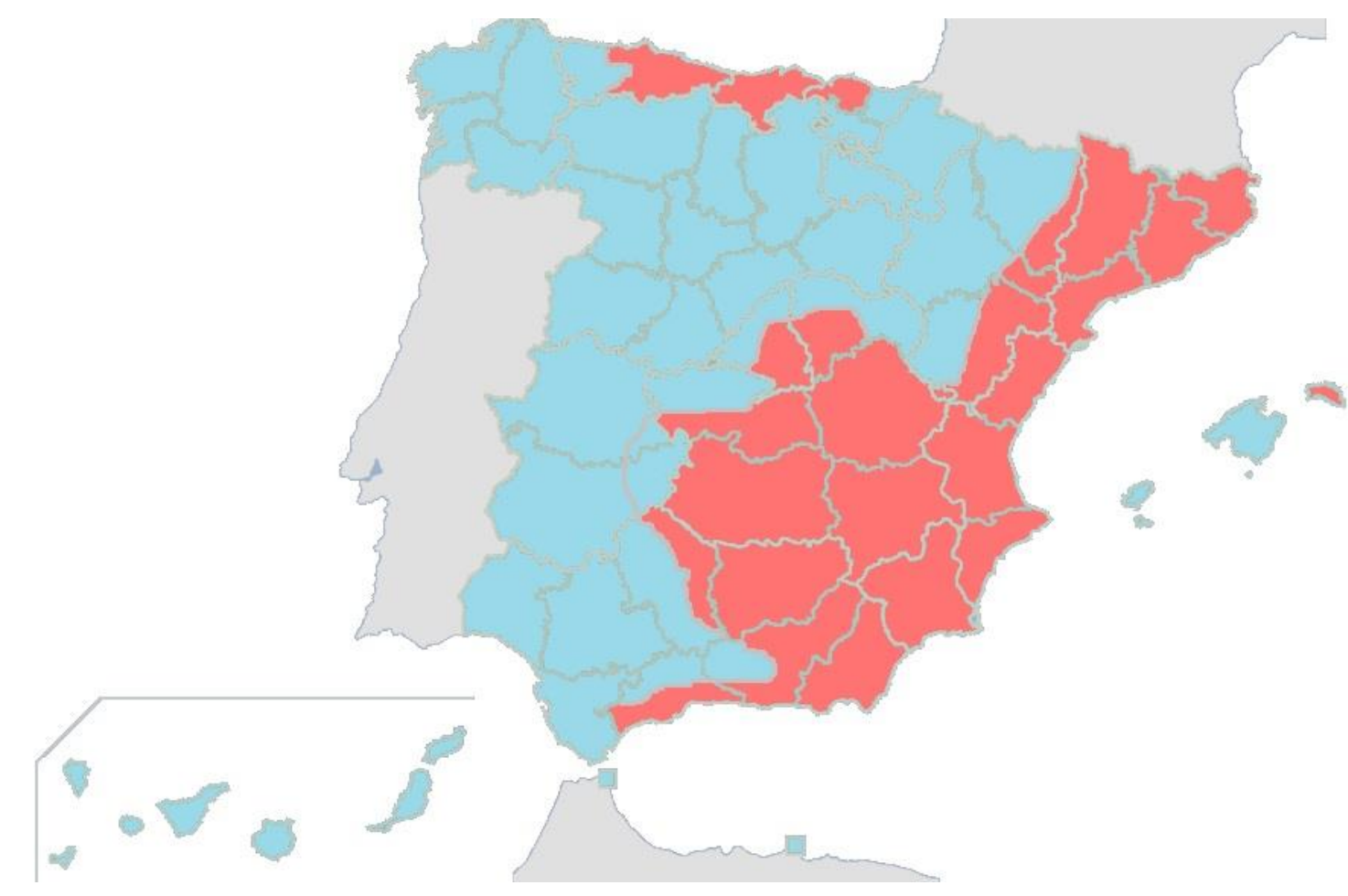

Zona controlada por el Gobierno de la República

Zona controlada por los militares sublevados

Fuente: elaborado a partir de Graham, Helen, Breve historia de la guerra civil, Gran Austral, Madrid, 2006.

La rebelión militar de julio de 1936 no triunfó, pero tampoco había sido derrotada. En las zonas donde triunfó, prácticamente en toda la España interior, Galicia y la Andalucía del Guadalquivir, es decir, en las principales zonas agrarias del país, el poder quedó en manos del Ejército sublevado (Mapa 1). Disponer de las tierras que producían la mayoría de las subsistencias, como los cereales, quería decir que el problema de abastecer a la población civil y a las tropas estaba prácticamente resuelto desde el comienzo del conflicto ${ }^{26}$. En su contra inicial tuvo que las principales regiones industriales y productoras de textil, hierro, acero, minería de carbón se decantaron a favor de la España republicana. La caída de Bilbao, en junio de 1937, sin embargo, puso a disposición del Ejército rebelde la industria vizcaína intacta y, como ocurrió con todas las industrias de los territorios que iban siendo conquistados, fue inmediatamente militarizada y puesta al servicio del esfuerzo bélico. Justo lo que el Gobierno Vasco y, por extensión, el Gobierno republicano nunca hizo. La correspondiente Comisión Militar de Incorporación y

\footnotetext{
${ }_{25}$ Casanova, Julián y Gil Andrés, Carlos, Historia de España..., op. cit., págs. 180-181.

${ }^{26}$ Martínez Ruiz, Elena, “El campo en guerra..., op. cit., págs. 109-121.
} 
Movilización Industrial diseñó el plan de reconversión, para el que contó con el acuerdo y apoyo del consejo de administración de Altos Hornos de Vizcaya. La reacción de la industria fue inmediata: la producción de lingote de hierro se recuperó, en parte por la provisión de carbón desde Alemania y poco después desde Asturias, pero también porque los grandes empresarios vizcaínos supieron apreciar rápidamente las posibilidades de crecimiento $\mathrm{y}$ de futuros beneficios $^{27}$.

Frente al poder absoluto de los mandos militares en la zona rebelde, el Gobierno republicano no conseguía poner orden por la proliferación de autoridades milicianas dispersas por el territorio, que desmigajaron el poder político y con él las decisiones económicas y, lo que aún era más grave, las estrictamente militares. Qué era antes, si la revolución o la guerra, resultó ser una cuestión que rompió lo poco que quedaba de la unidad del Frente Popular, hundió al Estado y debilitó hasta el extremo la República ${ }^{28}$. Tras la caída del Norte, a la República le quedaba Cataluña. Convertida en el mayor centro industrial de la España republicana, en Cataluña se mantuvieron indemnes de la vorágine revolucionaria muchas fábricas y empresas, e incluso algunas de ellas mejoraron sus instalaciones. Se recuperó la capacidad productiva, pero sólo hasta 1938, cuando el aislamiento y la ocupación por los sublevados de las centrales de energía leridanas comenzaron a plantear problemas irresolubles de abastecimiento energético ${ }^{29}$. Para entonces, la situación económica de la República era cada vez más penosa. Los experimentos revolucionarios, la desorganización, el impacto de la guerra y el acuerdo de no intervención de las democracias europeas provocaron una caída de significativa de la producción, especialmente agraria (Tabla 3).

Tabla 3. Producción de cereales en la zona sublevada y republicana durante la Guerra Civil, 1936-1938

\begin{tabular}{|l|c|c|c|c|c|c|}
\hline \multirow{2}{*}{} & \multicolumn{2}{|l|}{ Zona sublevada } & \multicolumn{2}{l|}{ Zona republicana } \\
\cline { 2 - 7 } & 1936 & 1937 & 1938 & 1936 & 1937 & 1938 \\
\hline Trigo & 15.527 .100 & 21.175 .600 & 19.308 .200 & 12.583 .384 & 9.643 .280 & 8.000 .000 \\
\hline Cebada & 7.595 .200 & 9.841 .900 & 7.377 .300 & 8.778 .610 & 7.884 .944 & 7.000 .000 \\
\hline Centeno & 3.397 .200 & 4.524 .500 & 3.417 .400 & 565.030 & 489.903 & 400.000 \\
\hline Avena & 2.437 .230 & 3.599 .070 & 3.195 .620 & 1.944 .248 & 1.483 .654 & 1.300 .000 \\
\hline Maíz & 4.410 .600 & 5.268 .400 & 4.390 .950 & 1.484 .310 & 1.196 .618 & s.d. \\
\hline
\end{tabular}

Fuente: Martínez Ruiz, Elena, “El campo en guerra..., op. cit., pág. 114.

Aparte de las diferencias organizativas respecto a la producción, los sublevados entablaron una eficaz guerra monetaria. En noviembre de 1936 rompieron la circulación de la peseta al ordenar el estampillado de billetes como requisito imprescindible para que pudieran circular legalmente por su territorio, e invalidaron los puestos en circulación en la zona republicana después del 18 de julio. Para marzo de 1937 se dispuso la emisión de nuevos billetes, ordenándose el canje de los anteriores estampillados por los nuevos. Los republicanos contestaron prohibiendo los billetes de

${ }^{27}$ Catalan, Jordi, "Guerra e industria..., op. cit., pág. 199; y Torres, Eugenio, "Los empresarios: entre la revolución y la colaboración”, en Martín Aceña, Pablo y Martínez Ruiz, Elena (eds), La economía de la guerra civil, Madrid, Marcial Pons, 2006, págs. 431-460.

${ }^{28}$ Casanova, Julián y Gil Andrés, Carlos, Historia de España..., op. cit., págs. 194-203.

${ }^{29}$ Catalan, Jordi, “Guerra e industria..., op. cit., pág. 179. 
la zona sublevada. La existencia de dos monedas, la peseta de la República y la emitida desde la zona insurgente, motivó que se rompiera en dos la circulación monetaria ${ }^{30}$. Las noticias que desde Radio Nacional se emitían sobre la "moneda buena" y la "mala" acentuaron el atesoramiento en el lado republicano, al tiempo que los rebeldes sacaban partido de aquel dinero que consideraban ilegal y de nulo valor: con él consiguieron divisas, hundiendo la cotización de la peseta en el exterior y pagaron servicios de información en el extranjero. Con todo ello contribuyeron a la inflación que acompañó a la guerra en el lado republicano, y que supo contenerse, por el contrario, en el lado franquista (Tabla 4). Las entidades bancarias, por tanto, se vieron afectadas no sólo por la división del territorio y la dispersión de sus redes de sucursales que hacía imposible llevar una contabilidad en orden, sino también por la guerra monetaria.

Tabla 4. Índices de precios en la zona sublevada y republicana durante la Guerra Civil, 1936-1939

\begin{tabular}{|c|c|c|}
\hline & $\begin{array}{l}\text { Precios al por mayor en la } \\
\text { zona sublevada }\end{array}$ & $\begin{array}{l}\text { Precios al por mayor en la } \\
\text { zona republicana }\end{array}$ \\
\hline 1936 & 100,0 & 100,0 \\
\hline 1937 & 120,6 & 546,0 \\
\hline 1938 & 137,4 & $1.354,1$ \\
\hline 1939 & 140,7 & $1.528,4$ \\
\hline
\end{tabular}

Fuente: Martín Aceña, Pablo, “La economía de la guerra civil..., op. cit., pág. 27.

Desde el inicio de la guerra, los sublevados dieron órdenes que ilegalizaban todas las decisiones del Banco de España republicano y reivindicaron la legítima representación de la entidad en territorio "nacional". Aunque los financieros eran defensores de la sublevación contra el Gobierno del Frente Popular, éstos veían con recelos a los falangistas más radicales, en cuyo programa, en el punto 26, figuraba la nacionalización de la banca. Finalmente, no se produjo la nacionalización, pero la banca quedó supeditada a las decisiones político-militares mientras duraron las hostilidades. Frente a la élite financiera, el Gobierno republicano contaba al comenzar la guerra con las importantes reservas de oro depositadas en el Banco de España, en Madrid. En septiembre de 1936, cuando se temió una caída inminente de la capital, el presidente de la República, Manuel Azaña, firmó un decreto autorizando al ministro de Hacienda para que transportara el oro a un lugar más seguro, y se trasladó a la base naval de Cartagena. En octubre, cuando los sublevados calificaron esta decisión como un delito de traición y se pusieron en contacto con algunos de los bancos europeos más importantes para denunciar aquel "despojo", el Gobierno republicano decidió el envío del oro a la Unión Soviética. Un año y medio más tarde, en septiembre de 1938, el oro se había acabado. Todo se había ido en la adquisición de divisas y la satisfacción de deudas acumuladas por la República al servicio del esfuerzo bélico. De acuerdo con lo que hoy sabemos, puede afirmarse que el llamado "oro de Moscú" se esfumó con eficacia sólo relativa, ya que una parte sustancial se fue en la adquisición y pago de un material de guerra muchas veces obsoleto, aunque no cabe menospreciar la manipulación de los tipos de cambio que los soviéticos hicieron a la hora de fijar los precios de las mercancías que suministraban ${ }^{31}$. La historia del "oro de Moscú" dio desde entonces mucho que hablar, tantas como las opiniones

\footnotetext{
${ }^{30}$ Martorell, Miguel, "Una guerra, dos pesetas", en Martín Aceña, Pablo y Martínez Ruiz, Elena (eds), La economía de la guerra civil, Madrid, Marcial Pons, 2006, págs. 329-356.

${ }^{31}$ Martín Aceña, Pablo, "El sistema financiero..., op. cit.
} 
sobre el papel que ejercieron la política de no intervención de Francia y Gran Bretaña y el apoyo económico-militar de la Italia mussoliniana y la Alemania nazi a los sublevados ${ }^{32}$.

\section{E1 deterioro del bienestar humano}

La Guerra Civil alteró la evolución de la economía española tanto por los efectos negativos que comportó en el crecimiento económico, como por la ruptura del mercado interior. Pero al coste económico ocasionado por el conflicto, hay que añadir también las víctimas de la guerra (bajas en los combates, represión política, malnutrición, enfermedades y bombardeos) y el deterioro de las condiciones de vida y salud de la población. La represión de la Guerra Civil en ambas retaguardias ha sido objeto desde los años noventa de excelentes estudios, lo que facilita algunas conclusiones definitivas. Una evidencia que puede establecerse a raíz de tales estudios es que, en uno y otro lado, al menos durante los primeros meses, los del verano de 1936 de manera muy intensa, se tiñeron de una violencia extrema. En las zonas donde triunfó la rebelión militar, el Ejército procedió a la destitución, encarcelamiento y muchas veces el fusilamiento de las autoridades republicanas, así como la prisión o la eliminación física de los líderes de las organizaciones obreras y de los partidos políticos de la izquierda. En la zona republicana, milicias y comités sindicales se convirtieron en los auténticos amos y desencadenaron una sangrienta depuración contra cualquier símbolo del poder económico, político o religioso, pero también contra las personas. En general, el Gobierno republicano asistió atónito e impotente a la represión y los paseos incontrolados ${ }^{33}$.

En el ámbito de las condiciones de vida y salud, España protagonizó durante el primer tercio del siglo XX un notable proceso de modernización social, impulsado por el avance de los procesos de transición demográfica, epidemiológica, nutricional, alfabetización y urbanización. Durante este periodo, las caídas en la mortalidad general --del 28,9 al 16,8\% - y en la mortalidad infantil del $204,4 \%$ al $123,8 \%$ - se hacen seguir pronto de la disminución de la natalidad -del 33,8\% al $28,2 \%{ }^{34}$. El progreso de las tasas vitales discurrió paralelo a la reducción de la morbilidad. El descenso de este último se debió casi por completo a la reducción de la importancia de enfermedades infecciosas y las transmitidas por el agua y los alimentos, así como a las mejores condiciones de las infraestructuras higiénico-sanitarias ${ }^{35}$. La urbanización, a su vez, revela también la dinámica de un cambio en profundidad: las poblaciones de más de 10.000 habitantes, que albergaban a algo menos de un tercio del total de la población al comienzo del siglo, dan domicilio a más de la mitad en 1930. Este crecimiento urbano fue especialmente intenso en las ciudades de más de 100.000 habitantes, resultado en parte de los intensos movimientos migratorios interiores, las cuales doblan en esos treinta años el total de su población ${ }^{36}$. Igualmente debe destacarse el gran esfuerzo que en el campo de la educación se hace durante las tres primeras décadas del siglo. En 1930 la tasa de alfabetización total aumentaría en un tercio, pasando del $43 \%$ en 1900 al $71 \%$ en 1930 (en hombres del 55\% al 80\% y en mujeres del $32 \%$ al $63 \%$, respectivamente) ${ }^{37}$.

\footnotetext{
32 Casanova, Julián y Gil Andrés, Carlos, Historia de España..., op. cit., págs. 185-192.

${ }^{33}$ Sobre la represión de la Guerra Civil en ambas retaguardias véase Juliá, Santos (Coord.), Victimas de la Guerra Civil, Madrid, Temas de Hoy, 1999.

${ }^{34}$ Nicolau, Roser, "Población, salud y actividad", en Carreras, Albert y Tafunell, Xavier (eds.), Estadísticas Históricas de España, Barcelona, Fundación BBVA, 2005, págs. 77-154.

35 Sanz Gimeno, Alberto y Ramiro Fariñas, Diego, "Infancia, mortalidad y niveles de vida en la España interior. Siglos XIX y XX”, en Martínez Carrión, José Miguel (ed.), El nivel de vida en la España rural, Siglos XVIII-XX, Alicante, Universidad de Alicante, 2002, págs. 359-403.

36 Silvestre, Javier, "Internal migrations in Spain, 1877-1930”, European Review Economic History, 9 (2), 2005, págs. 233265.

${ }^{37}$ Núñez, Clara Eugenia, “La educación”, en Carreras, Albert y Tafunell, Xavier (eds.), Estadísticas Históricas de España, Barcelona, Fundación BBVA, 2005, págs. 157-244.
} 
La Guerra Civil, como aconteció en la economía, ocasionará una brusca interrupción de tales procesos de cambio social que sólo se retomarán pasado el ecuador de la centuria. Entre 1936 y 1939, la mayoría de la población española conoció una fuerte regresión de su bienestar humano. Los indicadores de demografía, estado nutricional, índices sintéticos del bienestar y educación expresan, sin lugar a dudas, que es con la Guerra Civil cuando se produce en España un deterioro de las condiciones de vida y salud. Desde el siglo XIX las sociedades europeas occidentales experimentaron un descenso en sus tasas de mortalidad y de fecundidad, consiguiendo un progresivo aumento de la esperanza de vida, dentro de un proceso conocido como "transición demográfica" ${ }^{38}$. Aunque los ritmos y niveles que presenta este proceso variaron de unos países respecto a otros, España, pese a las condiciones de retraso que caracterizaron su proceso de transición demográfica, no fue ajena a la caída de la mortalidad y la mejora de las condiciones de salud. La investigación demográfica de las últimas tres décadas muestra que los primeros decenios del siglo XX fueron de una clara reducción de la mortalidad en general, e infantil en particular. Únicamente los años de la pandemia de gripe de 1918-1920 y los de la Guerra Civil de 1936-1939 presentan una elevación de la mortalidad lo suficientemente importante como para alterar la tendencia y frenar el claro proceso de caída de la mortalidad que se había iniciado en el último tercio del siglo XIX ${ }^{39}$ (Gráfico 4).

Gráfico 4. Tasas brutas de natalidad, mortalidad y crecimiento natural en España, 19251940 (tasas por 1.000 habitantes)

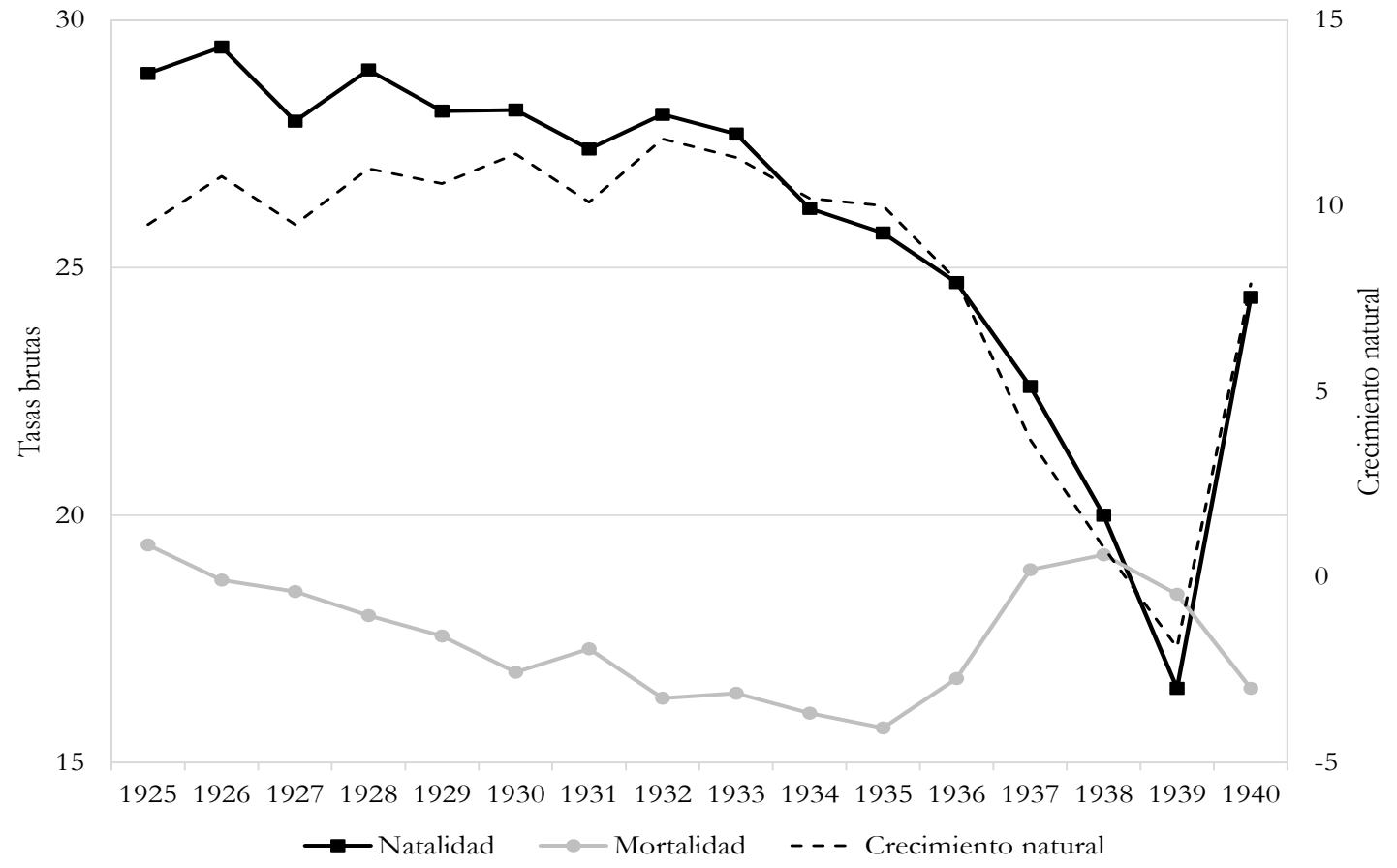

Fuente: Nicolau, Roser, “Población, salud..., op. cit. pág. 125. Elaboración propia.

La Guerra Civil alteró todas las estructuras sociales, económicas y demográficas del país y sus efectos sobre la mortalidad se tradujeron en un importante retroceso en el que se alcanzaron niveles de mortalidad propios de la década de los años veinte ${ }^{40}$. Las edades más jóvenes también

${ }^{38}$ Floud, Roderick, Fogel, Robert W., Harris, Bernard, Hong, Sok Ch., The Changing Body: Health, Nutrition, and Human Development in the Western World since 1700, Cambridge University Press, Cambridge, 2011.

${ }^{39}$ Sanz Gimeno, Alberto y Ramiro Fariñas, Diego, “Infancia, mortalidad..., op. cit., págs. 373-379.

40 Del movimiento natural de la población española de los años 1936 a 1939, las cifras de defunciones son las más discutibles, debido a la deficiente inscripción en el registro civil de las muertes violentas. En la introducción al 
se vieron afectadas por el empeoramiento de las condiciones de vida y del entorno, sobre todo por los problemas de alimentación y cuidados maternos e higiénicos-sanitarios, así como por la mayor incidencia de las enfermedades infecciosas, cuya influencia se vio favorecida por la contienda ${ }^{41}$. Entre 1936 y 1939, la tasa de mortalidad infantil (primer año de vida) pasó del 114,0 por 1.000 a 140,3 por $1.000^{42}$. La falta progresiva de alimentos, su mala calidad y su escaso valor nutritivo provocaron la carencia de aporte vitamínico y calórico y la debilidad física de la población, por lo que la mortalidad asociada a la desnutrición experimentó un importante crecimiento $^{43}$. Enfermedades como la clorosis - producida por la escasez o falta de ciertas vitaminas- y, especialmente, la avitaminosis - producida por deficiencia de hierro en la dieta, y caracterizada por anemia con palidez verdosa y otros síntomas- se propagaron entre la población, agravado todo ello por las malas condiciones de salubridad. El empeoramiento de las condiciones de salud y epidemiológicas, con su correlato en un incremento de la morbi-mortalidad, tuvo su réplica en la esperanza de vida al nacer ${ }^{44}$. Como puede observarse en la Tabla 5, la esperanza de vida al nacer de la población española se estancó (50 años) entre 1930 y 1940, mientras aumentó (7 años) entre 1900 y 1910, y avances de dimensiones similares se produjeron en los años veinte (8,8 años). Por sexos, los datos muestran que las consecuencias directas de la guerra recayeron sobre todo en los hombres. La esperanza de vida al nacer de la población masculina descendió (1,3 años) entre 1930 y 1940.

Tabla 5. Esperanza de vida al nacer de la población masculina, femenina y total española, 1900-1940 (años y décimas de año)

\begin{tabular}{|c|c|c|c|}
\hline & \multicolumn{2}{|l|}{ Hombres } & \multicolumn{2}{l|}{ Mujeres } & \multicolumn{1}{l|}{ Total } \\
\hline 1900 & 33,9 & 35,7 & 34,8 \\
\hline 1910 & 40,9 & 42,6 & 41,7 \\
\hline 1920 & 40,3 & 42,1 & 41,2 \\
\hline 1930 & 48,4 & 51,6 & 50,0 \\
\hline 1940 & 47,1 & 53,2 & 50,1 \\
\hline
\end{tabular}

Fuente: Nicolau, Roser, "Población, salud..., op. cit., pág. 86.

movimiento natural de 1939 (publicado en 1943) se estimaba, entre 1936 y 1939, un total de 330.000 defunciones causadas por la guerra. Esta estimación de la Dirección General de Estadística mejoraba la realizada por Villar (1942), que a partir de datos provisionales había avanzado, un año antes, un mínimo de 250.000 defunciones. Al mínimo estimado por la Dirección General de Estadística (330.000 defunciones) debiera añadirse el elevado porcentaje de muertes no registradas. Díez Nicolás (1985) estimó un total de 344.000 defunciones en los años 19361939, atribuibles a la guerra, y a éstas (344.000) les añadió cerca de 244.000 defunciones más correspondientes a los años 1940-1942 que, según este autor, no se habrían producido de haber proseguido la tendencia descendente, en la evolución de la mortalidad, observada hasta el inicio de la guerra. Las últimas estimaciones, presentadas por Ortega y Silvestre, indican una sobremortalidad de 540.000 personas, en Ortega, José Antonio y Silvestre, Javier, "Las consecuencias demográficas", en Martín Aceña, Pablo y Martínez Ruiz, Elena (eds), La economía de la guerra civil, Madrid, Marcial Pons, 2006, pp. 53-105.

41 Gómez Redondo, Rosa, La mortalidad infantil española en el siglo XX, Madrid, Siglo XXI, 1992.

${ }^{42}$ Nicolau, Roser, "Población, salud..., op. cit., pág. 131.

${ }^{43}$ Del Cura, Ma Isabel y Huertas, Rafael, Alimentación y enfermedad..., op. cit. y Castelló, Isabel, "Evolución de la mortalidad asociada a desnutrición en la España contemporánea: 1900-1974”, Revista de Demografía Histórica, XXVIII, II, 2010, págs. 25-49.

44 La esperanza de vida al nacer es el número de años que viviría una persona de una generación que estuviera sometida a las condiciones (o niveles) de mortalidad de un año determinado (en nuestro caso durante los años de la Guerra Civil). 
Las consecuencias demográficas de la guerra no se limitaron solo a sus efectos sobre la mortalidad y las enfermedades, sino también sobre la natalidad, fecundidad y nupcialidad (Gráfico 4). Villar (1942) estima que el número de nacimientos perdidos por causa de la Guerra Civil alcanzó la cifra de 613.000, entre 1936 y 1939. En la introducción al movimiento natural de 1939 (publicado en 1943) se estima una pérdida de 436.000 nacimientos en los mismos años. De la combinación de ambas estimaciones y de la corrección de las cifras (provisionales) utilizadas por Villar se deduce que el número de nacimientos perdidos por la guerra no fue superior a los $516.000^{45}$. Las últimas estimaciones presentadas por Ortega y Silvestre (2006) indican una caída de la natalidad de 576.000 nacimientos. Según estos autores, la Guerra Civil, además, supuso una alteración muy fuerte en los movimientos migratorios. Por un lado, porque el conflicto provocó grandes movimientos de población desplazada hacia el exterior, principalmente de exiliados y refugiados que cruzaron, no sin penalidades en muchas ocasiones, la frontera francesa ${ }^{46}$. Y, por otro lado, porque la guerra frenó una evolución ascendente de las migraciones interiores que, a diferencia de las exteriores, habían aumentado considerablemente durante los años veinte ${ }^{47}$.

El deseo por ampliar y evaluar otros aspectos del estado de salud de la población ha motivado en las últimas décadas la búsqueda y utilización de nuevos indicadores, destacando las medidas antropométricas, en particular la estatura. A partir de las investigaciones de variados autores entre los que podemos destacar a Robert Fogel, John Komlos, Richard H. Steckel, Roderick Floud, Jorg Baten y, para el caso español, José Miguel Martínez Carrión, se ha podido establecer que la estatura es un excelente indicador del nivel de salud y del estado nutricional de las poblaciones humanas en todos los contextos. Así, el estudio histórico de las proporciones y medidas del cuerpo humano, especialmente la estatura, ha dado lugar a todo un campo de estudio conocido como 'historia antropométrica'. Convertida en una de las líneas de investigación más activas y competitivas de la historia económica desde los años noventa, la historia antropométrica tiene como principal objetivo estudiar los cambios en el estado nutricional a partir de la estatura y otros indicadores biométricos, y analizar el impacto de los procesos socioeconómicos y los cambios institucionales sobre el bienestar biológico y la salud de las poblaciones ${ }^{48}$.

En este campo se insertan los estudios españoles que desde la década de 1990 se han venido realizando por autores como Martínez Carrión, Pérez Castejón y Gloria Quiroga y, a partir de la década de 2000, por investigadores como Javier Moreno, Josep Maria Ramon, Antonio D. Cámara, Javier Puche, Héctor García, Pedro M. Pérez Castroviejo, José Cañabate, Ramón y Maribel Ayuda, basados, como la mayoría de los trabajos realizados en otros países, en las fuentes de reclutamiento militar y que dan cuenta de la evolución de la estatura de los mozos españoles entre los 19 y 21 años desde las generaciones nacidas a mediados del siglo XIX hasta finales del siglo XX, entre otros aspectos, como las desigualdades sociales y territoriales y los determinantes del crecimiento.

Como indicador del estado nutricional, ¿cuál fue la evolución de la estatura de los mozos españoles durante los años de la Guerra Civil? ¿Hubo un deterioro de las condiciones de nutrición? En el Gráfico 5 aparece la tendencia de la estatura media anual de los mozos españoles y del Sureste español entre las cohortes nacidas en 1904 y 1940 (eje horizontal primario), y que corresponden a las generaciones que vivieron sus reemplazos militares entre los años 1925 y 1961 (eje horizontal secundario). Las dos series antropométricas permiten evaluar el impacto

\footnotetext{
${ }^{45}$ Los datos en Nicolau, Roser, "Población, salud..., op. cit., pág. 81.

46 Serrano, Secundino, "Exiliados. La odisea de los refugiados de la Guerra Civil española", Historia y Vida, 553, 2014, págs. 26-45.

47 Ortega, José Antonio y Silvestre, Javier, “Las consecuencias demográficas..., op. cit., págs. 97-98.

48 Martínez-Carrión, José Miguel, "Living Standards, Nutrition and Inequality in the Spanish Industrialisation. An Anthropometric View", Revista de Historia Industrial, 64, 2016, págs. 11-50.
} 
nutricional que tuvo la Guerra Civil durante la infancia y la adolescencia de las sucesivas cohortes de reclutas. La serie española de estatura, formada por una muestra de casi 47.000 estaturas de todas las regiones entre las cohortes de 1874 y 1933, ha sido elaborada por Quiroga (2002) a partir de los datos provenientes de las Hojas de Filiación, conservados en el Archivo General Militar de Guadalajara ${ }^{49}$. La serie del Sureste español, por su parte, está formada por una muestra de casi 187.000 estaturas entre las cohortes de 1840 y 1948, y ha sido construida por Martínez Carrión y Pérez Castejón (2002) a partir de los datos disponibles a escala local de 12 municipios del Sudeste español (provincias de Alicante, Almería y Murcia) ${ }^{50}$.

Gráfico 5. Evolución de la estatura media en España y el Sureste español, cohortes de nacimiento de 1904-1940 (reemplazos militares de 1925-1961)

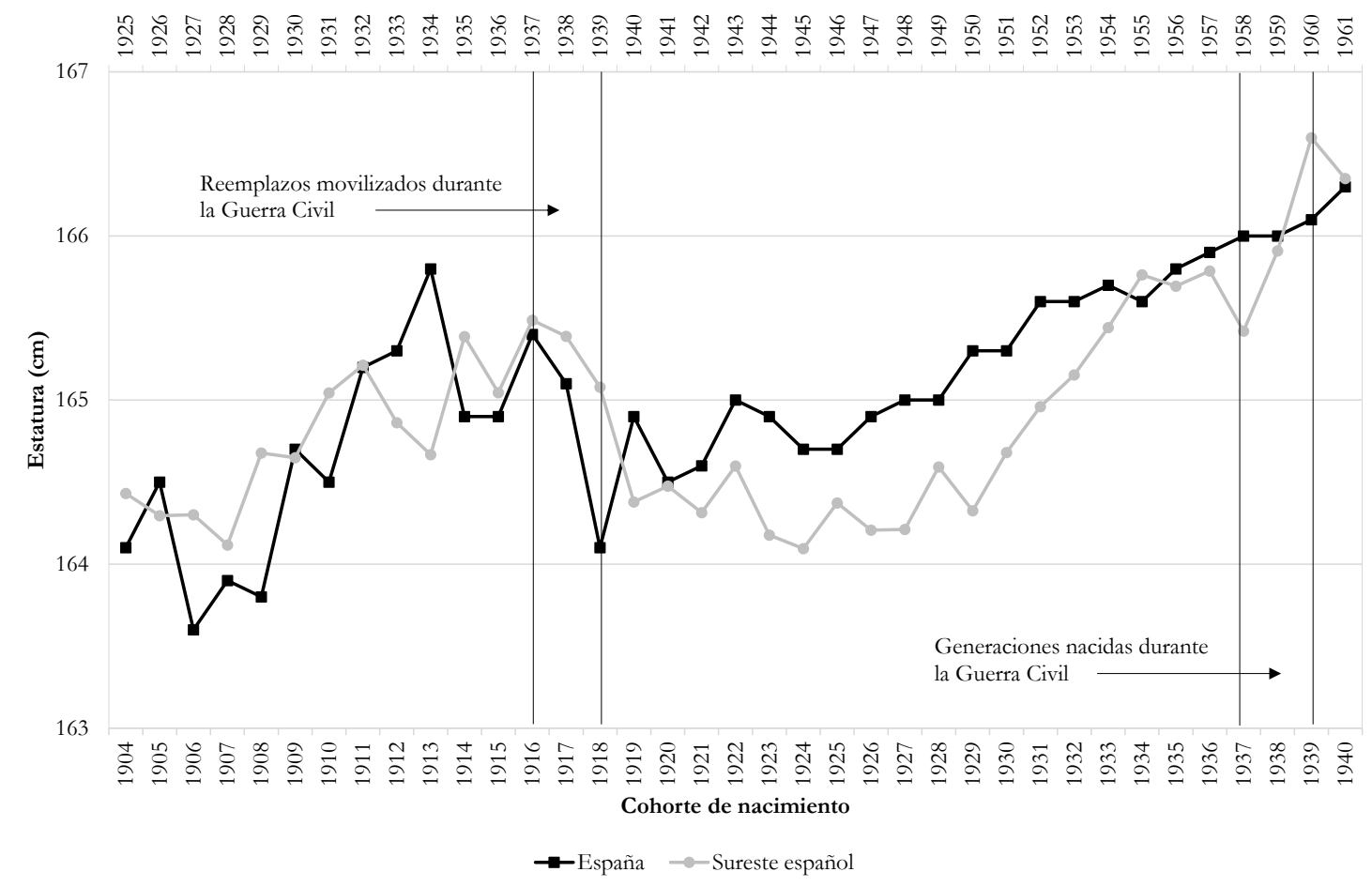

Fuente:Quiroga, Gloria, Medidas antropométricas..., op. cit.; y Martínez-Carrión, José Miguel y Pérez-Castejón, Juan José, "Creciendo con desigualdad..., op. cit. Los datos en Nicolau, Roser, "Población, salud..., op. cit. pág. 137. Elaboración propia.

El Gráfico 5 muestra que, en el medio plazo, la talla media de los mozos españoles y del Sureste español creció entre las cohortes nacidas a comienzos y mediados del siglo XX, al pasar de 164,3 centímetros (cm) en 1904-05 a 166,3 cm en 1939-40. Hubo, por tanto, un incremento de $2 \mathrm{~cm}$ entre ambos periodos. Se trata, no obstante, de un aumento modesto si se compara tanto con el coetáneo de otros países europeos como con el que se produce entre el final de la autarquía franquista y el final del siglo (más de $9 \mathrm{~cm}$ ). Con todo, el crecimiento de $2 \mathrm{~cm}$ entre ambas fechas demuestra que existieron mejoras relativas en las condiciones de nutrición y en los niveles de bienestar biológico de las poblaciones masculinas españolas. Este incremento fue paralelo al

49 Quiroga, Gloria, Medidas antropométricas y condiciones de vida en la España del siglo XX, Tesis doctoral, Universidad A Alcalá de Henares, 2003.

${ }^{50}$ Martínez-Carrión, José Miguel y Pérez-Castejón, Juan José, “Creciendo con desigualdad. Niveles de vida biológicos en la España rural mediterránea desde 1840”, en Martínez-Carrión, José Miguel (ed.), El nivel de vida en la España rural. Siglos XVIII-XX, Alicante, Universidad de Alicante, 2002, págs. 405-460. 
avance registrado por los procesos de transición demográfica, epidemiológica y nutricional. Pero a pesar de esta mejora, el crecimiento de la estatura y la mejora del nivel de vida biológico no fueron sostenidos.

Los datos evidencian la existencia de ciclos que alteran el ritmo de crecimiento, registrándose el mayor deterioro entre las cohortes finales de la década de 1910 y mediados de la de 1920 (Gráfico 5). Son las generaciones que vivieron su adolescencia y sus reemplazos militares durante la Guerra Civil y la autarquía franquista de los años cuarenta, en los años más duros del primer franquismo. La serie nacional sugiere que las generaciones nacidas entre 1916 y 1918 (reemplazos de la guerra) sufrieron intensamente los efectos del conflicto bélico. Durante esos años la estatura media de los reclutas españoles cayó casi 1,5 cm. El peor registro se sitúa en la cohorte de 1918, la del reemplazo de 1939. Hasta 1952 no se recuperaron los niveles alcanzados en los reclutamientos de 1937. Se hace evidente que el empeoramiento general de las condiciones sanitarias y epidemiológicas y las privaciones alimentarias de la guerra ${ }^{51}$, muy graves en estas edades del crecimiento (estirón adolescente), tuvieron un impacto muy negativo en el estado de salud y en las condiciones de nutrición de los mozos, aunque no cabría menospreciar la repercusión que, en los años de infancia, pudo tener el aumento del coste de la vida en los años de la Primera Guerra Mundial y la epidemia de gripe de 1918-1920.

El Gráfico 5 revela asimismo que el deterioro antropométrico de la guerra fue más suave en la serie del Sureste español. Entre las cohortes de 1916 y 1918 (quintas de 1937-39) la talla media de los mozos del Sudeste español menguó solo en $0,4 \mathrm{~cm}$. La evidencia concuerda con la experiencia mostrada en otras regiones del Mediterráneo español durante los años del conflicto ${ }^{52}$. Aunque las principales regiones agrícolas del país se decantaron a favor de los sublevados, lo que pronto creó una situación de desigualdad respecto al abastecimiento de productos básicos ${ }^{53}$, la estructura de la propiedad de la tierra en algunas zonas ${ }^{54} \mathrm{y}$ la relativa tranquilidad que suponía la lejanía de los frentes de guerra ayudarían a explicar el impacto relativo de la Guerra Civil en el bienestar biológico de las poblaciones del Sudeste español y, por extensión, de la España rural mediterránea ${ }^{55}$. Por el contrario, el Gráfico 5 muestra que los mozos del Sureste español sufrieron

\footnotetext{
51 Estudios sobre la nutrición revelan una caída del consumo de energía y proteínas entre los años de la II República y comienzos de la década de 1950, en Cussó, Xavier, "El estado nutritivo de la población española, 1900-1970. Análisis de las necesidades y disponibilidades de nutrientes", Historia Agraria, 36, 2005, págs. 329-358.

52 Puche, Javier, "Evolución de los niveles de vida biológicos en la Comunidad Valenciana, 1840-1948", Investigaciones de Historia Económica, 7 (3), 2011, págs. 380-394.

53 Como cita Martínez Ruiz, al comienzo de la guerra, aproximadamente el 30\% del producto agrario estaba en manos republicanas (dentro de éste se incluía el $90 \%$ de los agrios, el 50\% del aceite, el 80\% del arroz y la mayor parte de la producción hortofrutícola). Se trataba en su mayor parte de productos de exportación, pero escaseaban muchos de los alimentos básicos de subsistencia, lo más importantes para el consumo interno. En la zona franquista, por su parte, quedaba el 70\% restante, que incluía las dos terceras partes de la cosecha triguera y de patatas, la mitad del maíz y el $60 \%$ de las leguminosas. También disponía de la mayor parte del ganado de leche y de tiro, el 75\% del vacuno, el 70\% del ovino y buena parte de la producción lanera, en Martínez Ruiz, Elena, "El campo en guerra..., op. cit., pág. 111.

${ }^{54}$ Eran en su mayoría regiones de predominio de la pequeña propiedad con explotaciones de alta y muy diversificada producción. Pese a ello, muchos campesinos, muchas veces reacios, fueron empujados a integrarse en las colectivizaciones agrarias. El movimiento de colectividades, no obstante fue menos importante en las regiones donde la agricultura estaba más orientada al mercado, sobre todo al exterior. En Valencia, por ejemplo, las colectivizaciones ocuparon pocas tierras y duraron poco tiempo, en Martínez Ruiz, Elena, “El campo en guerra..., op. cit., pág. 130.

55 En la zona controlada por los sublevados, precisamente la de mayor reserva de recursos trigueros, los escasos estudios regionales llevados a cabo han revelado también que el impacto biológico de la Guerra Civil no fue tan acusado. Con todo, y aunque se observa una leve caída de la talla de los mozos castellanos leoneses en los reemplazos de 1937-41, se ha documentado que el porcentaje de mozos excluidos por falta de talla aumentó entre los reclutas de 1957-61 y 1967-69, correspondiente a las cohortes nacidas durante de la Guerra Civil y la autarquía de los años cuarenta, lo que sugiere que las carencias nutricionales también pudieron afectar a la zona "nacional", en
} 
más privaciones alimentarias en los años de la posguerra. Como resultado, hasta 1955 no recuperaron los niveles antropométricos alcanzados en los reclutamientos de 1937. Esta penalización de la autarquía franquista discurrió paralelo al incremento de la desigualdad biológica. Los resultados alcanzados en otras investigaciones realizadas en la España mediterránea muestran que, si tomamos como referencia las generaciones que vivieron su adolescencia en los tiempos más difíciles - los de la Guerra Civil y la posguerra-, los mozos alfabetizados mejoraron sus niveles relativos de bienestar biológico mientras que empeoraron para los analfabetos al experimentar mayores pérdidas. Los progresos en la reducción de la desigualdad social se vieron truncados de nuevo por la Guerra Civil y las políticas franquistas, afectando de forma muy negativa a los grupos sociales más desfavorecidos ${ }^{56}$.

¿Qué ocurrió con las cohortes nacidas en la Guerra Civil? A juzgar por los datos representados en el gráfico 5, y lejos de lo cabría pensar en lo que respecta a las nefastas condiciones de guerra, las poblaciones infantiles no se vieron muy afectadas por el conflicto. Entre las cohortes de 1936 y 1939, la estatura media de los mozos españoles y del Sureste español creció $0,2 \mathrm{~cm}$ y $0,8 \mathrm{~cm}$, respectivamente. La interpretación que se hace de los datos por cohortes de nacimiento requiere en todo caso cautela, aunque estos sugieren que las generaciones masculinas nacidas en los traumáticos años de la Guerra Civil y la autarquía franquista ya pertenecen a un ciclo de progreso sostenido de la estatura. No es de extrañar puesto que los supervivientes al conflicto bélico y al desastre de la autarquía vivieron su adolescencia en la década de 1950 en la que se asistió a una progresiva estabilización del principal input del balance nutricional (el alimentario) ${ }^{57}$, junto con ciertos progresos sanitarios (por ejemplo, la extensión de los antibióticos, la penicilina y la difusión de nuevas vacunas $)^{58}$. Son generaciones que, por tanto, tuvieron cierto margen de recuperación de los más que presumibles estados carenciales vividos durante la primera infancia bajo la Guerra Civil y la autarquía franquista ${ }^{59}$.

Junto a las indudables ventajas de la renta por habitante, la mortalidad infantil y la estatura, existen también otros indicadores sintéticos de desarrollo y bienestar que han emergido con fuerza desde finales del siglo XX. De todos ellos el más conocido es el Índice de Desarrollo Humano (IDH), que es un producto del Programa de Desarrollo de las Naciones Unidas. Combina tres indicadores: esperanza de vida al nacimiento, tasa de alfabetización y renta per cápita. El IDH, que pretende ser una medida sintética del desarrollo humano, comprende los logros de cada nación en esperanza de vida, nivel educativo y nivel de vida a través de varios índices individuales que se ponderan en una escala de mínimos y máximos. El índice final se obtiene mediante una media aritmética simple de los tres valores. Para el caso español, contamos con los resultados obtenidos por Escudero y Simón ${ }^{60}$.

Moreno-Lázaro, Javier y Martínez-Carrión, José Miguel, "La evolución de la estatura en una región atrasada de la España interior: Castilla y León 1830-1960”, Hispania, 231, 2009, págs. 221-225.

56 Martínez-Carrión, José Miguel y Puche, Javier, “Alfabetización, bienestar biológico y desigualdad: la Comunidad Valenciana, 1850-1970”, Historia Agraria, 47, 2009, págs. 167-186.

${ }^{57}$ Cussó, Xavier, "El estado nutritivo..., op. cit.

${ }^{58}$ Nicolau, Roser, "Población, salud..., op. cit., pág. 89.

59 Los estudios publicados sugieren que los años de la Guerra Civil fueron perniciosos para los nacidos en los municipios del Levante valenciano. Entre las cohortes de 1936 y 1940, la estatura de las poblaciones infantiles valencianas se redujo $0,6 \mathrm{~cm}$. También se perciben efectos negativos en los nacidos en las zonas catalanas, en Martínez-Carrión, José Miguel, Puche, Javier y Ramon-Muñoz, Josep Maria, "Nutrición y desigualdad social en la España de Franco: evidencia antropométrica”, en Segura, Antonio, Mayayo, Andreu y Abelló, Teresa (Dirs.), La dictadura franquista. La institucionalizació d’un règim, Barcelona, Universitat de Barcelona, 2012, págs. 271-284.

${ }^{60}$ Escudero, Antonio y Simón, Hipólito, "Nuevos datos sobre el bienestar en España”, en Chastagnaret, Gérard, Daumas, Jean Claude, Escudero, Antonio y Raveux, Oliver (Eds.), Los niveles de vida en España y Francia (siglos XVIIIXX), Alicante, Universidad de Alicante y L’Université de Provence, 2010, págs. 213-251. 
¿Cuál fue la tendencia del IDH español durante la Guerra Civil española? ¿Afectó el conflicto bélico al proceso de convergencia respecto a los principales países de la Europa occidental y los Estados Unidos? La Tabla 6 y el Gráfico 6 presentan la evolución del Índice de Desarrollo Humano (IDH) de España entre los años 1900 y 1940 tanto en términos absolutos como relativos, según las estimaciones de Escudero y Simón y Prados de la Escosura, respectivamente $^{61}$. En general, en las dos medidas presentadas del IDH (absoluta y relativa respecto a la media de los países de Europa occidental, y respecto a Estados Unidos-) España experimentó un notable progreso a lo largo del primer tercio del siglo XX, sobre todo en la década de 1920. En términos absolutos, partiendo de un nivel bajo en 1900 -0,360- España alcanzó, en 1930, un índice de 0,549 (Tabla 6). Entre ambas fechas, España pasó de ser un país con IDH bajo a una nación con IDH medio -que son aquellos países cuyo IDH se sitúa entre los índices 0,500 y 0,799-. La variable que mejor se comportó fue la esperanza de vida -34,9 en 1900 y 49,9 en 1930- gracias a varias causas: por un lado, a una mejora general del estado nutricional y, por otro lado, a un mayor gasto del Estado en políticas de salud pública (infraestructuras higiénico-sanitarias, control bromatológico de los alimentos...). Esta variable, no obstante, descendió ligeramente en la década de 1910 como consecuencia de los efectos mórbidos de la pandemia de gripe de 1918-1920, haciendo que el IDH aumentara muy poco en ese decenio. La tasa de alfabetización, por su parte, pasó del 43,9\% al 68,9\%, superando desde 1910 al componente renta en valores índices. La presión del movimiento regeneracionista iniciado en España a fines del siglo XIX, de republicanos y socialistas desembocó en la creación en 1902 del Ministerio de Instrucción Pública y en una mayor financiación de la educación primaria, que dejó de ser responsabilidad de los municipios para incorporarse a los presupuestos generales del Estado. Pese al sorpasso del indicador educación, la renta per cápita también mostró un destacado progreso, acorde con el avance del proceso de crecimiento económico (Tabla 6).

Tabla 6. Índice de Desarrollo Humano de España, 1900-1940

\begin{tabular}{|c|c|c|l|l|l|c|l|}
\hline & \multicolumn{2}{|l|}{ Valores originales } & \multicolumn{2}{l|}{ Índices } & \\
\hline & $\begin{array}{l}\text { Esperanza } \\
\text { de vida }\end{array}$ & $\begin{array}{l}\text { Tasa de } \\
\text { alfabetiza- } \\
\text { ción (\%) }\end{array}$ & $\begin{array}{l}\text { Renta per } \\
\text { cápita } \\
\text { (dólares } \\
\text { PPA) }\end{array}$ & $\begin{array}{l}\text { Esperanza } \\
\text { de vida }\end{array}$ & $\begin{array}{l}\text { Tasa de } \\
\text { alfabetiza- } \\
\text { ción (\%) }\end{array}$ & $\begin{array}{l}\text { Renta per } \\
\text { cápita } \\
\text { (dólares } \\
\text { PPA) }\end{array}$ & IDH \\
\hline 1900 & 34,9 & 43,9 & 1744,6 & 0,165 & 0,439 & 0,477 & 0,360 \\
\hline 1910 & 41,5 & 49,7 & 1871,4 & 0,275 & 0,497 & 0,489 & 0,420 \\
\hline 1920 & 41,3 & 57,1 & 2142,1 & 0,272 & 0,571 & 0,511 & 0,451 \\
\hline 1930 & 49,9 & 68,9 & 2605,5 & 0,415 & 0,689 & 0,544 & 0,549 \\
\hline 1940 & 50,1 & 76,8 & 2046,8 & 0,418 & 0,768 & 0,504 & 0,563 \\
\hline
\end{tabular}

Fuente: Escudero, Antonio y Simón, Hipólito, “Nuevos datos...”, op. cit., pág. 220.

\footnotetext{
${ }^{61}$ Escudero, Antonio y Simón, Hipólito, “Nuevos datos..., op. cit.; y Prados de la Escosura, Leandro, El progreso económico..., op. cit.
} 


\section{Gráfico 6. IDH español en relación con el de la Europa occidental y Estados Unidos,} 1900-1938

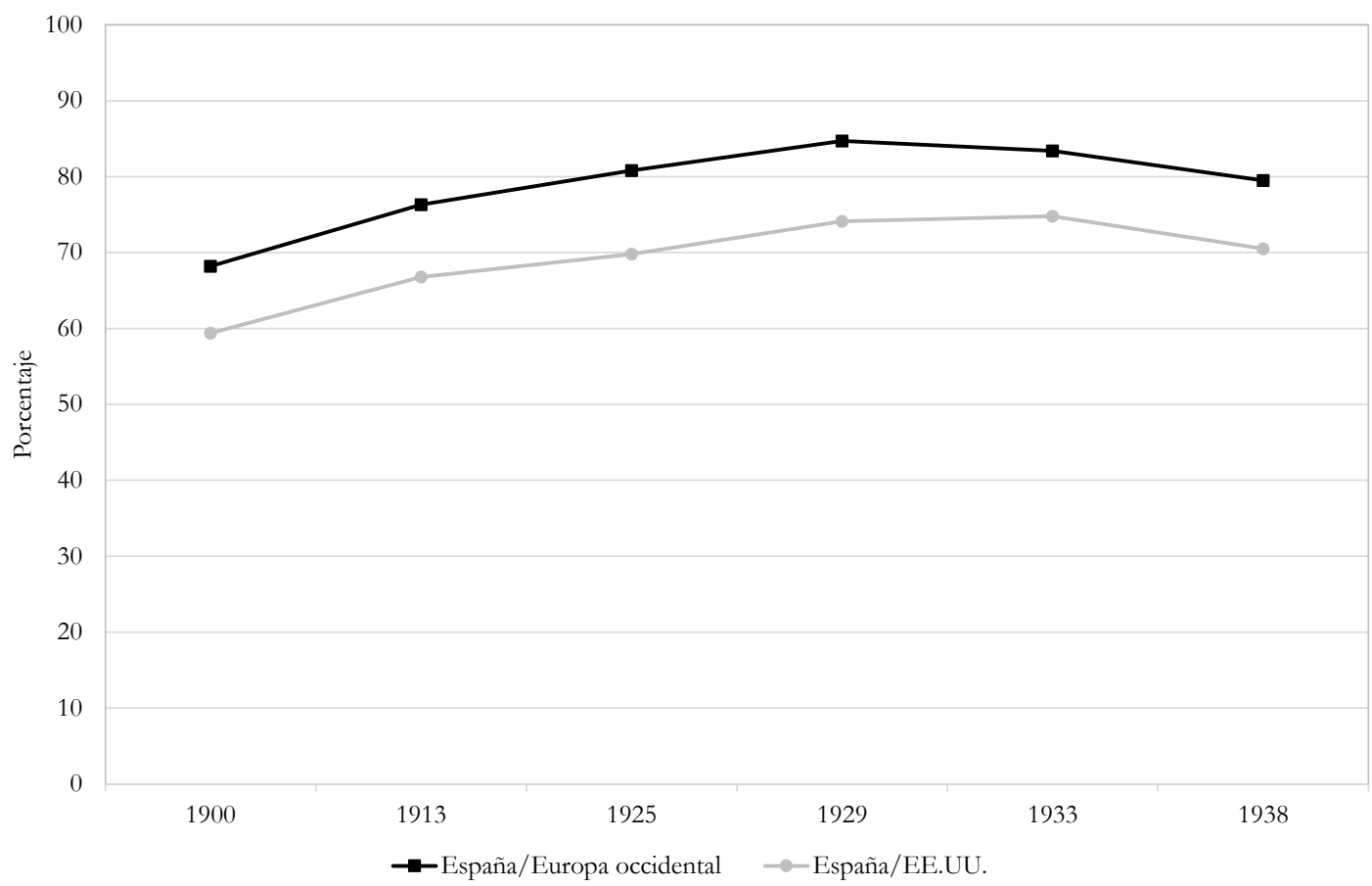

Fuente: Carreras, Albert; Prados de la Escosura, Leandro y Rosés, Joan R., “Renta...”, op. cit., pág. 1374. Elaboración propia

La tendencia ascendente del IDH español desde 1900 quedó truncada en la década de 1930, debido en parte al impacto del Gran Depresión en la economía española y, sobre todo, a los efectos de la Guerra Civil (Tabla 6). El estancamiento de la actividad productiva durante la primera mitad de los años treinta, coincidiendo mayormente con la II República, tuvo su réplica en la renta por habitante. Con la Guerra Civil, el estancamiento del quinquenio republicano se transformó en un desplome imparable de las principales macromagnitudes económicas (Tabla 1 y 2). El deterioro es bien visible en los datos del PIB per cápita, en particular durante los años de 1936-1938 (Gráfico 1). A esta evolución tan negativa del nivel de vida le acompañó la evolución desfavorable de la esperanza de vida. Ésta aumentó muy poco en los años treinta -49,9 en 1930 y 50,1 en 1940 - como resultado de las consecuencias demográficas de la Guerra Civil. Entre 1936 y 1939, como ya se ha señalado, la tasa de mortalidad infantil (primer año de vida) pasó del 114,0 por 1.000 al 140,3 por 1.000 debido al empeoramiento de las condiciones de salud y epidemiológicas y los problemas de alimentación. El impacto conjunto de todos estos factores provocó el estancamiento de la esperanza de vida. La tasa de alfabetización, en cambio, presentó una evolución distinta a la de la renta y la esperanza de vida, puesto que aquella mejoró durante el primer quinquenio por el mayor gasto público de la República en enseñanza primaria (Tabla 6). Hacia 1940 la tasa de alfabetización de la población española se acercaba al 80\%. Sin embargo, los avances educacionales observados durante el primer tercio del siglo XX se interrumpieron durante el primer franquismo ${ }^{62}$.

Por último, en términos relativos, y en comparación con Europa occidental y Estados Unidos, puede observarse que la convergencia en términos de IDH fue progresiva durante las primeras décadas del siglo XX (Gráfico 6). Si en 1900 el IDH de España era tan sólo el 59,4\% y 68,2\% de

${ }^{62}$ Núñez, Clara Eugenia, “La educación..., op. cit., págs. 164-165. 
la media estadounidense y europea, respectivamente, tres décadas después, hacia 1933, ya había ascendido hasta el 74,8\% y el 83,4\%, impulsado por los procesos de crecimiento económico y modernización social. El Gráfico 6 muestra que los rasgos depresivos de la crisis económica internacional de los años treinta y, más aún, los efectos socioeconómicos provocados por la Guerra Civil retrasaron en varios años la convergencia con Europa occidental y Estados Unidos en desarrollo humano, retrocediendo a niveles de IDH propios de los años veinte.

\section{Conclusiones}

Este artículo ha ofrecido una visión de conjunto sobre el impacto que la Guerra Civil de 19361939 tuvo en la economía española y en el bienestar humano de los españoles. La evidencia cuantitativa ha mostrado que el conflicto bélico fue desastroso en términos macroeconómicos y que las magnitudes colectivas o globales que miden la economía y la riqueza de los españoles, como la renta nacional, las actividades productivas, el comercio exterior, las inversiones o la renta per cápita experimentaron un claro deterioro. Este último resume del modo más expresivo sus consecuencias últimas: cuando termina 1939, el último año de la guerra, la renta real per cápita de los españoles había retrocedido, en términos reales, a los niveles de comienzos del siglo XX. Varios lustros, pues, perdidos, en términos de ganancia de bienestar económico y de convergencia con Europa. También entre 1935 y 1939 el nivel previamente alcanzado de convergencia real de España con la Europa más próspera -Reino Unido, Francia, Alemania e Italia- no dejó de caer -del 64,6\% al 42,8\% entre ambos años-, necesitándose después bastantes años más, hasta comienzos de la década de 1970, para recuperar la cota inicial. El fracaso del golpe de Estado militar y su conversión en Guerra Civil supuso, además, otra consecuencia inmediata desde el punto de vista económico: la ruptura de la unidad de un mercado interior que había funcionado hasta entonces de manera integrada. Su división por la fuerza de las armas provocó enormes trastornos en el funcionamiento de la actividad económica.

Junto al impacto económico, entre 1936 y 1939 la mayor parte de la población española conoció una fuerte regresión de sus condiciones de vida y salud. El análisis de los principales indicadores de salud e índices sintéticos (tasa bruta de mortalidad, mortalidad infantil, esperanza de vida, estatura e IDH) muestra que el estado de salud, el estado nutricional y el bienestar humano de la población española empeoraron durante los años de la Guerra Civil. La explicación de esta desfavorable evolución de tales indicadores reside en el empeoramiento de las condiciones de vida y epidemiológicas, con su correlato en un incremento de la morbilidad, la insuficiente atención sanitaria y médica, los problemas de alimentación y cuidados maternos -la congruencia con los datos de mortalidad asociada a desnutrición es muy elevada- y la represión que, sobre todo en el caso de los hombres, continuó durante toda la década de 1940 -la esperanza de vida al nacer de la población masculina descendió (1,3 años) en los años treinta-. Por todo ello se ha calificado la etapa de la Guerra Civil y del primer franquismo como nefasta desde el ámbito de la salud, la nutrición y el bienestar humano, que evidenciaron un claro retroceso.

En conclusión, las consecuencias de la Guerra Civil, su desenlace final y la autarquía franquista que le siguió supusieron, como ha esgrimido la historiografía económica española, que España perdiera el ritmo de crecimiento económico que había logrado desde comienzos del siglo XX, cayendo en una nueva fase de su historia caracterizada por la divergencia con la Europa avanzada y el mundo desarrollado en términos desarrollo económico y bienestar humano. 